\title{
Diversification of the economy in the context of globalization (case of Azerbaijan)
}

\author{
Esmira Ahmadova ${ }^{1}$, Lala Hamidova ${ }^{1 *}$, and Leyla Hajiyeva ${ }^{1}$ \\ ${ }^{1}$ Azerbaijan State University of Economics, Department of Economics, Istiglaliyyat, 6, Baku AZ1001, \\ Azerbaijan
}

\begin{abstract}
.
Research background: Azerbaijan, as a country with rich mineral resources, faces macroeconomic difficulties due to income instability. In 2011-2013, during the period of high world oil prices, Azerbaijan began to diversify the economy and develop the non-oil sector at the expense of oil and gas export revenues. The need to diversify the economy and export has become especially important in the conditions of increased global competition and the integration of the national economy into the world economy.

Purpose of the article: The aim of the issue is assessment and study the characteristics of diversification of the economy of Azerbaijan, analyze the dependence of the country's economic development on the degree of diversification of its economy and exports, assess the level of economic diversification of the country.

Methods: To measure the level of diversification, we used indicators such as Herfindahl-Hirschmann export diversification index, and industry concentration in GDP. The originality and value of the research lies in revelation a number of indicators specific to the Azerbaijani economy that affect economic growth based on correlation-regression analysis and other econometric methods. According to econometric characteristics, the resulting model is adequate and confirms the empirical findings

Findings \& Value added: The results of the study showed that deeper diversification of the economy is required. To overcome oil dependence and conduct effective economic diversification, it is necessary to develop processing industries, expand the accessibility of small and medium enterprises to financial resources, and stimulate foreign investment in the non-oil sector.
\end{abstract}

Keywords: economic diversification; export diversification; Azerbaijan; non-oil sector; natural resources

JEL Classification: $011 ; O 4 ; P 48$

${ }^{*}$ Corresponding author: lala_hamidova@unec.edu.az 


\section{Introduction}

Oil and gas exporting countries tend to be highly dependent on their dominant sector. This relationship has been a topic of discussion for many economists, scientists and researchers who put forward opposite theories. Research shows that the impact of natural resources on economic growth depends on how well a country is endowed with two types of capital that can be seen as complementary to natural resources: it is human capital and government management or institutional capital [1]. Natural resource wealth can provide opportunities for countries to build human and institutional capital.

In addition, supporters of economic dependence on energy resources to justify their point of view periods of high energy prices. Thus, in government structures, the point of view was popular that efforts to diversify the economy were not so necessary, that the country should adhere to its specialization in the international division of labor as a supplier of natural resources. The main argument was that the existence of advantage in this sector to other countries [2]. However, world oil prices are very volatile and the country's economy is very vulnerable during periods of fluctuations in world oil prices. In addition, instability in the commodity markets cannot provide the economy with stable sustainable development, and this is a fact that contradicts the UN Sustainable Development Goals.

In this regard, overcoming the dependence of the economy on the extractive sector by the authors of the article seems to be relevant in modern conditions, which is proposed in strengthening the diversification carried out in the country. One of the important criteria for successful diversification is the country's ability to smooth out high macroeconomic volatility and fluctuations in the real exchange rate of the manat (AR national currency).

According to the data of the State Statistics Committee of Azerbaijan Republic, the leading export products of Azerbaijan are mineral products. In the structure of Azerbaijan's exports in 2005-2018, the share of mineral products amounted to about $90 \%$. In 2018 , the share of crude oil and gas in the country's exports amounted to $84 \%$ [3].

The purpose of this article is to systematize the results of research based on the economic development of Azerbaijan oil production and an evaluation of the level of diversification. Since diversification can protect the national economy from external shocks, reduce volatility and ensure the stability of export earnings in the short term [4].

Although research and work on diversification has a relatively short history, in spite of this there are a lot of them. Most of this work positively evaluates the economic diversification patterns of resource-rich countries and supports the hypothesis that through diversification these countries can achieve the desired economic growth.

Numerous empirical views of researchers on diversification can be divided into the following groups: the impact of procurement of natural resources on economic growth; diversification of exports; link of institutions and diversification.

A number of studies have been devoted to the impact of natural resource provision on economic growth and country development $[1,5-8]$. One study indicates that over the past four decades, resource-exporting countries have been significantly inferior in development to less resource-rich countries [9]. Researchers attribute this to the fact that resourceextracting countries have to solve a number of specific problems: achieving economic stability in terms of uncertain and highly volatile budget revenues; reservation of production income for future generations; ensuring high quality investment of resource income in large investment projects, public consumption and subsidies [9].

Along with diversification of the economy, diversification of exports is also of great importance. These findings were made by Cadot, Carrere, \& Strauss-Kahn [10]. Using data from 159 countries for 1998-2004, they found a strong relationship between export concentration and per capita income: the higher the per capita income, the more diversified the export. 
The third group - defines the relationship between diversification and institutional factors. So, Omgba examined the institutional foundations of export diversification models in oil-producing countries [11]. The study measured difference in years between when the oil producing country began oil production and when the country gained independence. The study indicated that the larger the difference, the more oil producing country is involved in export diversification .

Balavac \& Pugh examined the role of trade openness, export diversification, and institutions as potential elements for predicting production volatility in 25 transition economies over the period 1996-2010 [12]. The econometric model used by Balavac \& Pugh shows the impact of resource provision, employment, and investment on economic growth. This empirical model indicates that GDP is used to determine economic growth. They noted that the effects of production instability may not be mitigated by diversification for countries with economies in transition that are at a medium or higher level of diversification, but may have positive results at lower levels of diversification. It was also noted that in order to stabilize production in countries with economies in transition, more advanced political institutions are needed. According to Alan Gelb, natural resources do not always have a negative impact on the economies of countries, but only if the institutions are weak [13].

Numerous studies on diversification of countries with rich natural resources have been published with the support of international financial institutions, in particular: "Diversified Development: Making the most natural resources of Eurasia" by World Bank [14]. Diversification studies in Azerbaijan were dedicated by Ahmadov; Aslanli, Aghayev, Ismayil, \& Mehtiyev; Bayramov \& Orujova; Hasanov; Ismayil [15-19].

In general, studies conducted by both foreign and local scientists, international reports describe diversification as an important and necessary step for resource-rich countries. It is also indicated that economic factors alone are not enough for successful diversification of the economy, political factors also play a special role.

\section{Methods}

The beginning of the analyzed period was taken in 1990 - the beginning of the independence of the Republic of Azerbaijan. The study covers 30 years - and is divided into 2 parts. Econometric modeling is based on a different composition of factors and covers the period from 1990-2019. The study is based on empirical data from the State Statistics Committee of the Republic of Azerbaijan. To calculate the Worldwide Governance Indicators (WGI), data from the World Bank were used [20].

The dependent variable in the article is the GDP of Azerbaijan. Based on the results of theoretical studies, the authors of the article took the following data as independent variables:

1. Ge - independent variable that measures the effectiveness of public administration. It is one of six indicators used to calculate the WGI. These indicators, calculated by the World Bank, reflect the level of management of a large number of respondents and expert assessments around the world and are the main ones in the methodological document WGI [20].

2. R - Rank of government effectiveness also takes into account management efficiency. The indicator refers to the world ranking of countries in terms of management efficiency.

3. Oil - oil production level, in thousand tons. The choice of this variable is based primarily on the fact that most of Azerbaijan's GDP consists of oil production. In 2018, the share of the oil sector in GDP was 40.2\%, and in 2010 - 48.1\% [3].

4. $\mathrm{Pr}$ - Oil price, dollars per barrel. Taken into account due to the fact that more than 
$70 \%$ of industrial productions in Azerbaijan make up crude oil and petroleum products.

5. U - dollar exchange rate to manat. Fluctuations in the exchange rate are closely related to oil prices. With high oil prices, the manat exchange rate is stable and at a high level. With the fall in world oil prices in 2014-2015, Azerbaijan experienced 2 devaluations of the manat. As a result of devaluation, the manat fell by $90 \%$ against the dollar.

6-7. Ii and Ie - these are domestic and foreign investments, in million manats. The inflow of domestic and foreign investment into the economy creates opportunities for job creation and brings additional economic activity to local economies.

8. L - employment (in thousand people) also affects economic growth: the higher the employment of the population, the higher the GDP produced in the country.

The need to develop trade with economic diversification in the context of the resource curse is emphasized in Collier and Venables collaborative study [21]. The assumption that trade plays an important role in the diversification of the economy, can be found in other studies [22]. Studies show that especially the diversification of exports leads to sustainable growth in the long term $[23,24]$. In this regard, retail trade is taken as an independent variable - $\mathrm{T}$ (in thousand manats).

Exporters of mineral raw materials have some peculiarities compared to countries rich in other natural resources. This relative limitation of production linkages with other sectors of the economy; highly concentrated natural resource rent, largely in the form of tax revenue [13]. In this regard, we introduce the independent variable Tx into the study - net taxes, in thousand manats.

Finally, the $11^{\text {th }}$ variable is export Ex. According to economic theories, higher exports mean more openness to trade, which implies higher profits.

Our theoretical model in general looks as follows:

$$
G D P=f(G e, R, O i l, P r, U, I i, I e, L, T, T x, E x)
$$

Or:

$$
\begin{gathered}
G D P=\alpha+\alpha_{1} G e+\alpha_{2} R+\alpha_{3} O i l+\alpha_{4} P r+\alpha_{5} U+\alpha_{6} I i+\alpha_{7} I e+\alpha_{8} L+ \\
+\alpha_{9} T+\alpha_{10} T x+\alpha_{11} E x+\varepsilon
\end{gathered}
$$

In addition to econometric analysis, in order to determine the level of economic diversification, the calculations of the Herfindahl-Hirschman Index (HHI) were carried out.

The HHI, calculated to determine the level of concentration of industries in GDP, was in the range of 0.19-0.29 in Azerbaijan for 2005-2018. The index took its maximum value in 2010 , during the peak of oil and gas production. In 2018, the HHI index was at 0.24 . Thus, Azerbaijan is characterized by a high level of concentration, and therefore, low diversification due to the fact that, as noted above, the share of mining industry prevails in the structure of GDP (Figure 1).

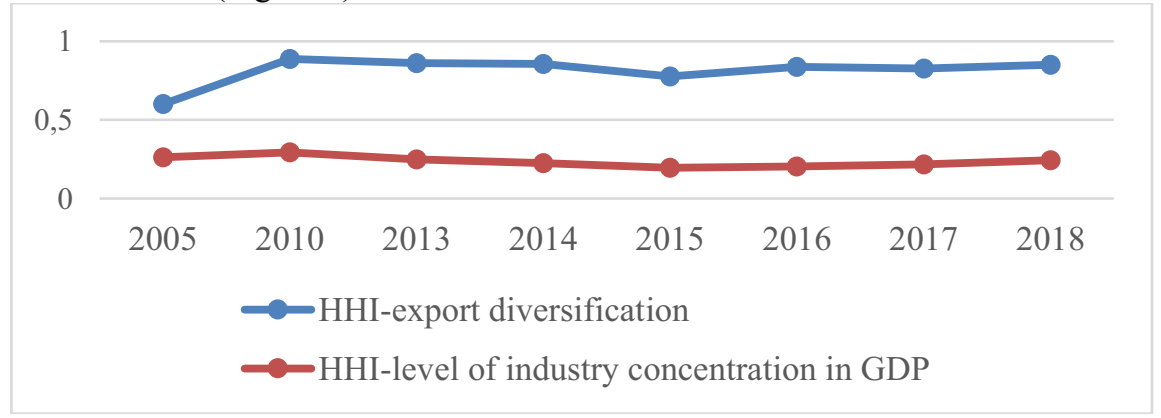

Fig. 1. HHI for calculating export diversification and the level of concentration of industries in GDP Source: author`s calculations 
The structure of exports by major commodity groups for 2005-2018 points to a more specialized export dominated by mineral products, of which the bulk is crude oil and gas. Calculations of the HHI show a low level of export diversification in Azerbaijan - 0.85 in 2018.

\section{Results}

For econometric modeling, we will use Poisson regression, which is used to predict the values of a binary dependent variable from a set of continuous or categorical dependent variables [25]. The calculations were performed on the basis of widely used modern software - the statistical environment $\mathrm{R}$, which is one of the most dynamically developing programs in its class. As a result of modeling based on data from 2002 to 2019 using the generalized linear modeling function, the following model $I$ was obtained:

$$
\begin{aligned}
G D P= & 2.4298+0.5459 * G e+1.0222 * R+1.00002 * O i l+1.0081 * P r+ \\
& +1.0414 * U+0.9999 * I i+1.00001 * I e+1.0016 * L+1.0000 * E x
\end{aligned}
$$

Where, Ge - Efficiency of public administration, R-rank in Ge, Oil - oil production, Pr oil price, U - dollar to manat, Ii - domestic investment, Ie - external investment, L employment, Ex - export goods.

Each regression coefficient is statistically significant at level $p<0.001$. It should be noted that the exponential parameters in the Poisson regression have the multiplicative rather than additive effect. It is needed to checked the model for excess dispersion.

Hypothesis 2:

$\mathrm{H} 0$ : there is excess variance.

$\mathrm{H} 1$ : there is not excess variance.

Table 1. Result of the over dispersion test.

\begin{tabular}{|c|c|c|c|}
\hline Over dispersion test & Obs. Var/Theor & Var Statistic & p-value \\
\hline Poisson data & 29087.33 & 843532.60 & 0.0 \\
\hline
\end{tabular}

Source: author`s calculations

The p-value turned out to be less than 0.05 levels, which indicates the presence of excess variance. There is no reason to reject hypothesis $\mathrm{H} 0$, then hypothesis $\mathrm{H} 1$ is rejected.

To reduce excess variance, let's re-evaluate the model. Therefore, after several iterations and elimination of insignificant variables, we obtain the following model II:

$$
G D P=1.0999+1.00003 * O i l+1.01 * P r+0.9999 * I i+1.0021 * L
$$

As a result of modeling the modified dataset, with the addition of independent variables $\mathrm{T}$ (trade) and Tx (taxes), based on data for 30 years from 1990 to 2019, using a generalized linear modeling function $(\mathrm{N}=30)$ (excluding the independent variables $\mathrm{Ge}$ and $\mathrm{R}$ due to the absence of these data before 2002) after 6 iterations, the following model $I I I$ was obtained:

$$
\begin{aligned}
& G D P=5.233523 e-05+0.9999 * T+1.0001 * I i+1.00003 * O i l+0.9983 * P r+ \\
& \quad+4.4132 * U+0.9997 * T x+0.9999 * I e+1.0045{ }^{*}+1.00001 * E x
\end{aligned}
$$

Where, T - Retail trade, Pr - average annual oil price in US dollars, Oil - oil production, $\mathrm{Pr}$ - oil price, $\mathrm{U}$ - dollar to manat exchange rate, Ii - domestic investments, Tx - net taxes, Ie - external investments, L - employment of the population, Ex - export of goods. 
As a result of further study and improve the model, after several iterations, and exclusion of insignificant variables from multiple linear model, we get the following model $I V$ :

$$
G D P=3.825+1.5581 * T+0.1986 * O i l+0.3202 * E x+8.962 * P^{*} * U
$$

Table 2. Econometric characteristics of model $I V$.

\begin{tabular}{|c|c|c|c|}
\hline $\begin{array}{l}\text { Coefficients: } \\
\text { (t-value) }\end{array}$ & $\operatorname{Pr}(>|t|)$ & Test & Test results \\
\hline Intercept $(4,609)$ & $0.000103 * * *$ & Multiple R-squared & 0.9958 \\
\hline $\mathrm{T} \quad(25,962)$ & $<2 \mathrm{e}-16^{* * *}$ & Adjusted R-squared & 0.9951 \\
\hline Oil $\quad(3,857)$ & $0.000714 * * *$ & F-statistic: & 1481 \\
\hline Ex $(6,243)$ & $1.57 \mathrm{e}-06 * * *$ & DF & 25 \\
\hline Pr*U $\quad(3,090)$ & $0.004863 * *$ & $\mathrm{~N}$ & 30 \\
\hline p-value: & $<2.2 \mathrm{e}-16$ & AIC & 545.6 \\
\hline DW & $\begin{array}{c}1.6 \mathrm{p} \text {-value }= \\
0.009946\end{array}$ & $\begin{array}{l}\text { Goldfeld-Quandt } \\
\text { test }\end{array}$ & $\begin{array}{c}107.3, \mathrm{df} 1=7, \mathrm{df} 2=7, \\
\text { p-value }=1.384 \mathrm{e}-06\end{array}$ \\
\hline Vif $(\bmod 2)$ & All variable $<10$ & & \\
\hline
\end{tabular}

Source: author`s calculations

In model $I V$, all parameters are significant at $\mathrm{p}$ level is less than 0.001 . They have a significant impact on the GDP and economic development of the republic.

Table 3. Assessment of the linear model 2 assumptions using the global test on 4 degrees-of-freedom: Level of Significance $=0.05$

\begin{tabular}{|c|c|c|c|}
\hline & Value & p-value & Decision \\
\hline Global Stat & 16.2813 & 0.664234 & Assumptions acceptable \\
\hline Skewness & 0.7406 & 0.389463 & Assumptions acceptable \\
\hline Kurtosis & 6.5398 & 0.610549 & Assumptions acceptable \\
\hline Link Function & 0.1325 & 0.715810 & Assumptions acceptable \\
\hline Heteroscedasticity & 8.8684 & 0.452901 & Assumptions acceptable \\
\hline
\end{tabular}

Source: author`s calculations

\section{Discussions}

According to model $I I I$, it can be seen that an increase in retail turnover by $0.1 \%$ increases GDP by a factor of 0.9999 , with other parameters unchanged. With an increase in domestic investment by 1 million manats, GDP will increase by 1.00003 times. The coefficient for the independent variable - external investment is 0.9997 . A decrease in GDP by $0.0003 \%$ can be expected, which indicates a low efficiency in the use of external investments or the need to revise domestic investment policy. The bulk of external investment goes to finance the extractive sector of the economy. Of all the factors, the exchange rate of the dollar against the manat has the greatest impact on GDP. Therefore, despite the volatility of prices in world markets, it is necessary to maintain a stable exchange rate for the national currency, the manat. Thus, an increase in the dollar exchange rate by 0.0001 cent can significantly affect the level of Azerbaijan's GDP.

Estimates for the parameters after the re-modeling is the same, but the large standard errors led to the fact that the value of the p-value for the exchange rate variables, domestic investment exceeded the 0.05 level. This suggests that, given the presence of excess 
variance, we do not have sufficient grounds to assert that they have a significant impact on GDP. Oil production, its price and retail turnover remained highly significant, suggesting that these variables have the greatest impact on GDP.

According to model $I V$, with an increase in oil production per unit, GDP increases by 0.1986 units, while other parameters remain unchanged. With an increase in exports per unit, GDP increases by 0.3202 units. Retail trade has a great influence on the gross product. Domestic investments turned out to be insignificant, which means that domestic investments are either distributed to the wrong sectors or their efficiency is very low. Interaction variable shows the total impact of oil price and manat / US dollar exchange rate on GDP. According to Model $I V$, this variable shows that the dependence of Azerbaijan's GDP on external factors (meaning world oil prices) and the exchange rate is very significant. Thus, as a result of the analysis of model $I V$, we come to the conclusion that the oil price is in the first place in terms of influence on the economic development of the country and on the GDP of Azerbaijan, and in second place is retail trade, in third place is exports, and in last place is oil production.

From the global test result in Table 3, it follows that the data satisfies all of the statistical assumptions underlying multiple regression analysis. It was possible to reduce the variance. The Variance Inflation Factor value is less than 10 for all variables, which indicates the absence of multicollinearity. The value of the Durbin - Watson criterion is about two - there is no autocorrelation of residuals in the model. The residues have a normal distribution, which indicates a good quality model $I V$.

\section{Conclusions}

As a result of research with the help of $\mathrm{HHI}$, an export specialized in mineral products was identified. According to the results of econometric models, despite the increased share of retail trade, taxes and a decrease in the extractive industry in the structure of Azerbaijan's GDP, the economy is still heavily influenced by independent variables such as oil prices and the exchange rate, which have a synergistic overall effect on GDP. It should be noted that individually, these factors are not significant. It was revealed that of the 11 indicators under consideration that affect GDP, some of the indicators are the main ones, while others are secondary. Econometric analysis based on the multiple regression models showed a strong relationship between Azerbaijan's GDP, oil price, exchange rate. These indicators are the paramount indicators, having a significant impact on GDP. The second (minor) group of indicators, which also affects economic development and GDP, is the export of goods, foreign investment, public administration efficiency and public administration rating, and others. Despite their small impact on GDP, nevertheless, their impact is present. To increase the influence of secondary factors on GDP, a deeper study of the development of each of these indicators is required

Thus, we come to the conclusion that economic diversification is proceeding at a slow pace. It must be understood that the abundance of natural resources should not impede successful economic development. The problems associated with the country's increased vulnerability to external shocks, the risk of Dutch disease are serious enough, but they can be solved with the help of appropriate institutions and policies.

The authors of the article propose the following: to carry out a deeper diversification of the economy of Azerbaijan; move away from a resource-based economy and increase the return on diversification measures; make a transition from the development of extractive industries to processing industries; stimulate foreign and domestic investment in non-oil sectors. The implementation of these measures will allow obtaining economic development in accordance with the Sustainable Development Goals. Successful diversification can 
protect the national economy from external shocks, reduce volatility and ensure the stability of export earnings in the short and medium term.

\section{References}

1. Hall, J. S., Sobel, R. S., Crowley, G. R. (2010). Institutions, Capital, and Growth. Southern Economic Journal, 77(2), 385-405.

2. Moiseyev, A. (2009). Diversifikatsiya ekonomiki resursodobyvayushchikh stran: i neobkhodimost' i vozmozhnosti. In Vestnik Instituta Ekonomiki Rossiyskoy Akademii Nauk (pp. 142-153). Moscow: Institut ekonomiki Rossiyskoy akademii nauk.

3. The State Statistical Committee of Azerbaijan Republic. Statistical Yearbook of Azerbaijan (1990-1999, 2000-2010, 2010-2019). Baku city.

4. Gelb, A., Grasmann S. (2010). How Should Oil Exporters Spend Their Rents? Working Paper 221. Center for Global Development. Retrieved from : http://www.cgdev.org/content/publications/detail/1424356

5. Gaitan, B., Roe, T. L. (2011). International trade, exhaustible-resource abundance and economic growth. Review of Economic Dynamics, 15, 72-93.

6. Alexeev, M., Chernyavskiy, A. (2015). Taxation of natural resources and economic growth in Russia's regions. Economic Systems, 39(2), 317-338.

7. Cavalcanti, T., Da Mata, D., Toscani, F. (2019). Winning the oil lottery: the impact of natural resource extraction on growth. Journal of Economic Growth, (24)1, 79-115.

8. Ben-Salha, O., Dachraoui, H., Sebri, M. (2018). Natural resource rents and economic growth in the top resource-abundant countries: A PMG estimation. Resources Policy. Retrieved from https://www.sciencedirect.com/science/article/pii/S0301420717304294

9. Gylfason, T., Zoega, G. (2002, June). Inequality and Economic Growth: Do Natural Resources Matter? Retrieved : https://papers.ssrn.com/sol3/papers.cfm?abstract_id=316620

10. Cadot, O., Carrere, C., Strauss-Kahn, V. (2013). Trade diversification, income, and growth: what do we know? ournal for Economic Surveys, 27, 790-812.

11. Omgba, L. D. (2014). Institutional foundations of export diversification patterns in oilproducing countries. Journal of Comparative Economics, 42(4), 1052-1064.

12. Balavac, M., Pugh, G. (2016). The link between trade openness, export diversification, institutions and output volatility in transition countries. Economic Systems, 40(2), 273287.

13. Gelb, A. (2010). Economic Diversification in Resource Rich Countries. Retrieved from : https://www.imf.org/external/np/seminars/eng/2010/afrfin/pdf/Gelb2.pdf

14. Gill I. S., Izvorski, I., Eeghen, W., Rosa D. (2014). Diversified Development: Making the most of natural resources of Eurasia. Full report. World Bank. Retrieved from : https://www.worldbank.org/content/dam/Worldbank/Feature\%20Story/ECA/diversifie d-development-eurasia-full-report.pdf

15. Ahmadov, I. (2017) Diversification problems of Azerbaijani economy: Obstacles and solutions. EDF, CIPE. Retrieved from

http://edf.az/uploads/documents/teqdimat_inqilab-ahmedov_diversifikasiya.pdf

16. Aslanli, K., Aghayev, R., Ismayil, Z., Mehtiyev, A. (2013). Azerbaijan: Assessment of economic and export diversification. Revenue Watch Institute. Public Association for Assistance to Free Economy. 
17. Bayramov, V., Orujova, L. (2017). Volatility, Diversification and Oil Shock in Resource-Rich Turkic Countries: Avenues for Recovery. Bilig, 83, 303-329.

18. Hasanov, F. (2013). Dutch disease and the Azerbaijan Economy. Communist and PostCommunist Studies, 46(4), 463-480.

19. Ismayil, Z. (2015). Oil Dependence and Challenges of the Economic Diversification. Retrieved from

http://freeeconomy.az/site/assets/files/1393/economic_diversification_challenge.pdf

20. Kaufmann D., Kraay A., Mastruzzi M. (2010). The Worldwide Governance Indicators: A Summary of Methodology, Data and Analytical Issues. Retrieved from : https://papers.ssrn.com/sol3/papers.cfm?abstract_id=1682130

21. Collier, P., Venables, A. J. (2007, April). Rethinking Trade Preferences: How Africa Can Diversify its Exports. Retrieved from : https://ssrn.com/abstract=1135500

22. Arezki, R., Ploeg, F. (2007, March). Can the Natural Resource Curse Be Turned Into a Blessing? The Role of Trade Policies and Institutions. Retrieved from : https://ssrn.com/abstract=969869

23. Hausmann R., Hwang J., Rodrik D. (2007). What you export matters. Journal of Economic Growth, 12(1), 1-25.

24. Lederman D., Maloney W. F. (2007). Does What You Export Matter? In search of empirical guidance for industrial policies. The World Bank. Retrieved from : https://openknowledge.worldbank.org/handle/10986/9371

25. Rosenblad, A., Faraway J. (2009). Extending the linear model with R: generalized linear, mixed effects and nonparametric regression models. Comput Stat., 24, 369-370. 